\title{
SISTEMAS DE INFORMAÇÃO GEOGRÁFICA NO ZONEAMENTO AMBIENTAL DO CAMPUS DA UFSCAR EM SÃO CARLOS: VEGETAÇÃO E HIDROGRAFIA
}

Nome do Autor (a) Principal

Bruna Caroline Marola

Nome (s) do Coautor (a) (s)

\section{Lígia Galdina Diniz Sepe; Edson Augusto Melanda}

Instituição ou Empresa

\section{Universidade Federal de São Carlos - UFSCar}

Agência de Fomento

CAPES - Coordenação de Aperfeiçoamento de Pessoal de Nível Superior

E-mail de contato: bcmarola@gmail.com

Palavras-chave

Geopreocessamento, Vegetação, Hidrografia

\section{INTRODUÇÃO}

Os Sistemas de Informação Geográfica (SIGs) são aplicativos computacionais que têm como objetivo o tratamento das informações relacionadas à superfície terrestre, auxiliando as combinações de dados pra diversas análises ambientais e urbanas. Essas informações são imprescindíveis no desenvolvimento de uma análise ambiental, especialmente quando os locais a serem analisados possuem áreas sensíveis a mudanças.

Segundo Cereda-Junior (2006), o meio ambiente não deve ser entendido como componentes separados que podem ser integrados pela simples soma de variáveis. A visão catalogada deve ser superada, uma vez que a caracterização e o levantamento de dados mutáveis não condizem com a realidade dinâmica e integrada que se materializa no espaço. É neste contexto que o uso de Sistemas de 
Informação Geográfica torna-se necessário para uma melhor compreensão do meio ambiente e seus componentes, integrando as diferentes variáveis de forma adequada.

Com a evolução dos SIGsdeu-se o crescimento de sua utilização nas análises espaciais, avaliando cenários geográficos com rapidez e agilidade, facilitando as tomadas de decisões. A utilização do SIG se divide em três fases, segundo DantasYamashita-Bartoli (1997):

- Fase 01: manipulação e divulgação de bancos de dados;

- Fase 02: operações analíticas de dados não gráficos e estrutura organizacional;

- Fase 03: análise espacial.

\section{OBJETIVOS}

Os objetivos deste projeto consistem na geração dados de principalmente sobre as vegetações e a hidrografia que compõem o campus da Universidade Federal de São Carlos, em seu campus Sede, para o auxílio do desenvolvimento do zoneamento ambiental através de plataformas gratuitas e de fácil manipulação.

A partir dos dados disponibilizados pela administração da Universidade, foram realizadas atividades de compatibilização e adequação para que estes pudessem ser utilizados em um SIG. Adicionalmente aos dados disponibilizados, a cobertura vegetal foi atualizada a partir de imagens de satélites. A partir de então, as atividades relacionadas a análise ambiental do campus da unidade sede da Universidade Federal de São Carlos com o emprego de plataformas gratuitas.

\section{METODOLOGIA}

Foram utilizados dois métodos diferentes, um para cada coleta de dados. Ambos consideravam o sistema de referência de coordenadas SIRGAS 2000 / UTM zona 23S, que significa que o sistema de projeção adotado é o UTM, com geóide do 
SIRGAS 2000 e que a área se encontra no fuso 23 , com meridiano central de $45^{\circ} \mathrm{W}$, onde localiza-se o campus que contém a região da unidade sede da Universidade Federal de São Carlos.

Para a hidrografia utilizou-se de um mapa em formato DWG com as informações adequadas sobre os cursos hídricos localizados no campus. Neste caso, a conversão foi feita após o isolamento das camadas relativas à hidrografia e ao limite do campus, utilizando o próprio AutoCAD e então utilizando a conversão de cada camada para o formato SHP no QGIS, selecionando o sistema de referências já citado.

No caso da vegetação, foi necessário o levantamento das informações relacionadas à cada uma das diversas espécies que compõem a cobertura vegetal do campus, entretanto, tais informações não estavamatualizadas no mapa disponibilizado. Desse modo, optou-se pela emprego da identificação manual destas informações, com apoio do aplicativo Google MapsEngine. No aplicativo estavam disponíveis imagens de satélite recentese pela criação de polígonos para cada tipo distinto de vegetação, foi possível atualizar o mapa da cobertura vegetal. Após a conclusão desta etapa, as informações foram exportadas para o aplicativo QGIS para análises espaciais.

\section{RESULTADOS}

Uma vez que os métodos de conversão foram definidos, foi possível transformar as informações em mapas específicos para cada tipo de análise. Por meio do mapa em DWG (AutoCAD®), da Autodesk $\AA$ ) foram criados os elementos para compor o mapa da hidrografia, com rios, lagos, áreas de nascente e os limites do campus, além da identificação de indústrias próximas a estes corpos hídricos para a análise de possíveis danos em áreas sensíveis, auxiliando o zoneamento ambiental na identificação de áreas de proteção permanente e os cursos d'água presentes no campus. A utilização do software QGIS através do processo de compor o mapa através de camadas em seu sistema de referências permitiu a criação de um novo mapa referente à hidrografia e respectivas Áreas de Proteção Permanente (APP) - discriminadas em internas e externas ao campus. Este mapa pode ser em 
pregado em estudos de conformidade com legislação ambiental, entre outras aplicações.

Figura 1: Mapa da hidrografia e APP do campus sede da Universidade Federal de São Carlos.

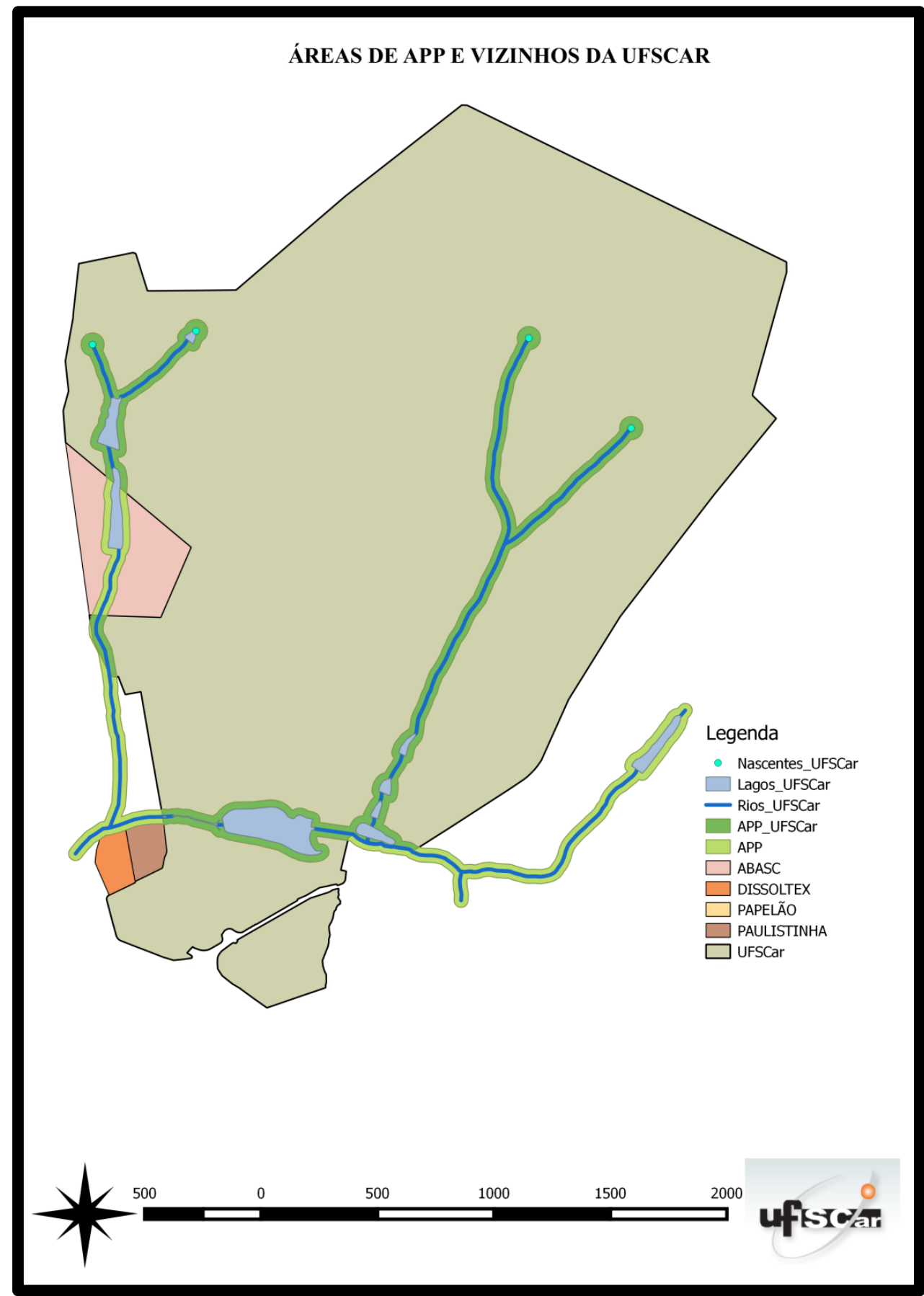

A elaboração do mapa das vegetações se deu de maneira semelhante, no entanto, o processo utilizado foi a digitalização de camadas através de polígonos formados na plataforma Google MapsEngine, exportados separadamente em formato KML para cada tipo de vegetação, previamente identificada com o auxílio 
das imagens de satélite e do conhecimento dos autores sobre a região. Este processo possibilitou a coleta de dados sobre as áreas e os perímetros de cada tipo de vegetação do campus, permitindo assim, uma análise ambiental muito mais completa. A construção do mapa foi feita também no software QGIS, que permitiu a composição de camadas e uma visualização mais ampla e clara dos aspectos referentes à vegetação. Neste mapa também foi utilizada a referência do limite da área que compõe o campus.

Figura 2: Mapa das vegetações do campus sede da Universidade Federal de São Carlos

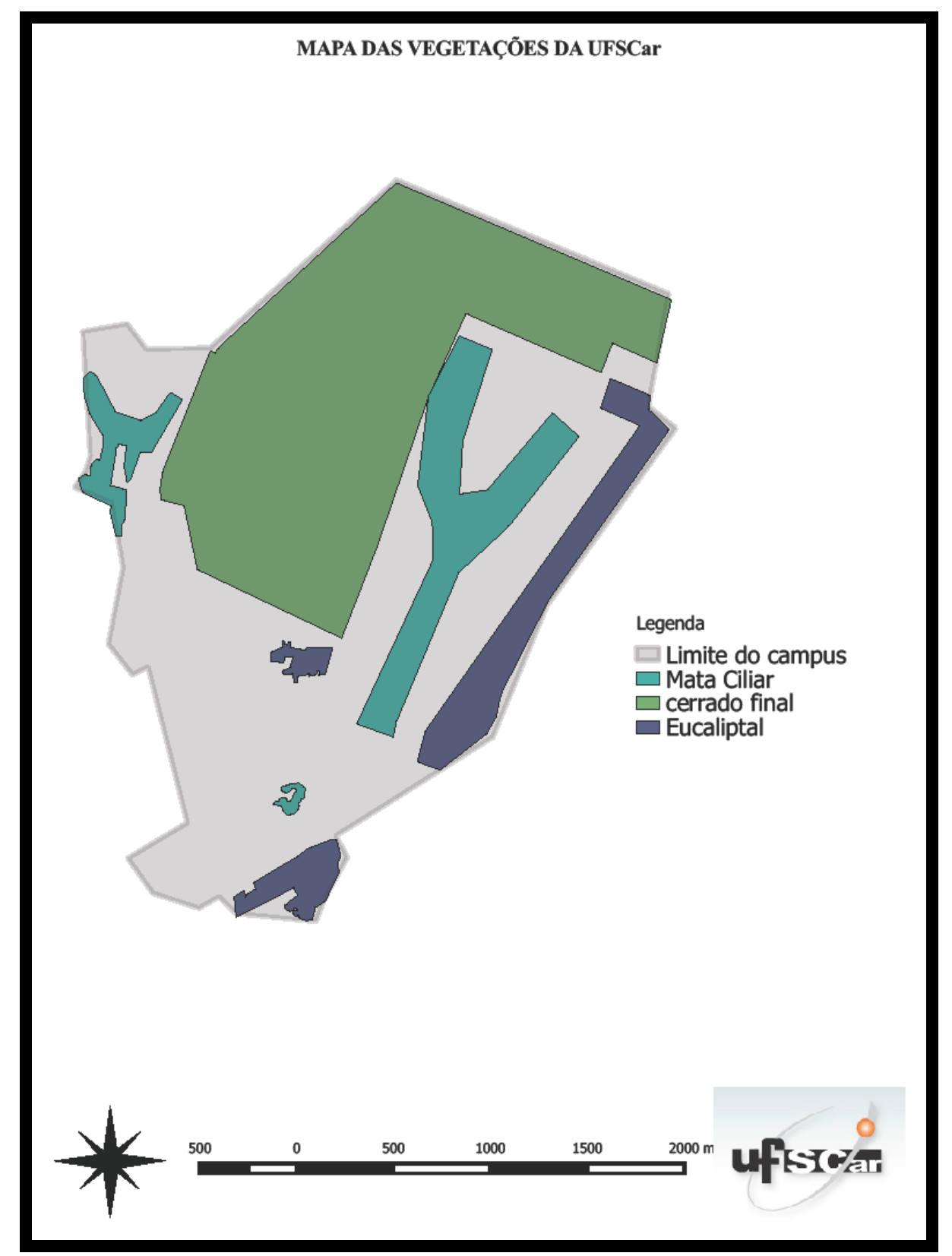




\section{CONCLUSÃO}

Com o desenvolvimento deste trabalho, foram produzidos e disponibilizados três novos mapas para o campus sede da Universidade Federal de São Carlos: hidrografia, Áreas de Preservação Permanente e Cobertura Vegetal. A utilização de ferramentas SIG gratuitas nosprocedimentos para conversão e integração dos dados, bem como para sua disponibilização à comunidade acadêmica, demonstra o excelente potencial destas no gerenciamento de campus universitários.

O estudo das ferramentas de apoio demandou algum tempo por se tratarem de vários aplicativos específicos da área. Somente após este estudo iniciou-se o processo de conversão e tratamento de dados de acordo com as necessidades solicitadas.

$\mathrm{Na}$ etapa de pré-processamento surgiram algumas dificuldades devido às exigências de cada tipo de mapeamento, demandando mais tempo que 0 inicialmente previsto para a execução dessa etapa. A utilização de duas maneiras diferentes de transformação de dados permitiu um maior conhecimento na área e proporcionou alguma habilidade em resolver problemas comuns do geoprocessamento de dados.

Atualmente, está sendo iniciada a etapa de análise para gerar mais mapeamentos específicos relacionados ao campus e suas características geográficas que também auxiliarão em seu zoneamento ambiental, como a declividade e as áreas asfaltadas ou construídas. Certamente serão necessários métodos diferentes de abordagem para as características citadas, tornando o desenvolvimento deste próximo projeto algo novo e diferente do que já foi apresentado.

\section{REFERÊNCIAS}

AUTODESK, Inc. Autocad download. Disponível em http://www.autodesk.com/products/autocad/ Acesso em 09/03/2015

CEREDA JUNIOR, A. Mapeamento da fragilidade ambiental na Bacia do Ribeirão do Monjolinho - São Carlos - SP- Utilizando ferramentas de geoprocessamento. Dissertação de Mestrado- UFSCar, 2007. 111p. 
DANTAS, A.; TACO, P. W. G.; YAMASHITA, Y. BARTOLI,S.P. Aplicações dos SIG em Transporte Sob o Enfoque da Análise Espacial. São Paulo, Brasil: IV Simpósio Brasileiro de Geoprocessamento, 1997. 469--477.

Google

MapsEngine,

Disponível

www.google.com/maps/d/edit?hl=pt\&mid=ziE6iBxHi48g.kiMTNAw-f4G8 Acesso em 06/02/2015

QGIS - Geographic Information System.Open Source Geospatial Foundation Project.

Disponível em http://qgis.osgeo.orgAcesso em 01/03/2015 